\title{
Hsa-miR-376c-3p targets Cyclin D1 and induces G1-cell cycle arrest in neuroblastoma cells
}

\author{
SWAPNIL PARASHRAM BHAVSAR ${ }^{1}$, CECILIE LØKKE ${ }^{1}$, TROND FLÆGSTAD ${ }^{1,2}$ and CHRISTER EINVIK ${ }^{1,2}$ \\ ${ }^{1}$ Pediatric Research Group, Department of Clinical Medicine, Faculty of Health Science, \\ The Arctic University of Norway-UiT, NO-9037 Troms $\varnothing ;{ }^{2}$ Department of Pediatrics, \\ Division of Child and Adolescent Health, University Hospital of North-Norway, NO-9038 Troms $\varnothing$, Norway
}

Received November 2, 2017; Accepted July 5, 2018

DOI: $10.3892 / \mathrm{ol} .2018 .9431$

\begin{abstract}
High-risk neuroblastoma is the most aggressive form of cancer in children. The estimated survival of children with high-risk neuroblastoma is $40-50 \%$ compared with low and intermediate risk neuroblastoma, which is $>98$ and $90-95 \%$, respectively. In addition, patients with high-risk neuroblastoma often experience relapse following intensive treatments with standard chemotherapeutic drugs. Therefore alternative strategies are required to address this problem. MicroRNAs (miRNAs/miRs) are small, endogenously expressed non-coding RNAs, which when deregulated have been demonstrated to serve significant roles in the tumorigenesis of a number of different types of cancer. Results from a previous deep sequencing study identified 22 downregulated miRNAs from the 14q32 miRNA cluster differentially expressed in neuroblastoma cell lines isolated from 6 patients at diagnosis and at relapse following intensive treatments. miR-376c-3p is one of the 22 miRNAs that was downregulated in the majority of the cell lines isolated from patients post treatment. The present study employed reverse transcription-quantitative polymerase chain reaction (RT-qPCR) to quantify the basic expression of miR-376c-3p in 6 neuroblastoma cell lines. The functional role of miR-376c-3p in the neuroblastoma cell lines was evaluated by alamar blue-cell viability and propidium iodide-flow cytometric assays. In addition, luciferase reporter assays, RT-qPCR and western blotting were performed to identify and quantify the targets of miR-376c-3p in neuroblastoma cell lines. Ectopic expression of miR-376c-3p led to
\end{abstract}

Correspondence to: Professor Christer Einvik, Pediatric Research Group, Department of Clinical Medicine, Faculty of Health Science, The Arctic University of Norway-UiT, Hansine Hansens veg 18, NO-9037 Troms $\varnothing$, Norway

E-mail: christer.einvik@uit.no

Abbreviations: miRNA, microRNA; NC, negative control; miR-376c-3p, microRNA-376c-3p; CCND1, Cyclin D1

Key words: high-risk neuroblastoma, microRNA, deep sequencing, 14q32 microRNA cluster, microRNA-376c-3p, Cyclin D1 significant inhibition of cell viability and G1-cell cycle arrest in multiple neuroblastoma cell lines by reducing the expression of cyclin D1, an oncogene critical for neuroblastoma pathogenesis. The results of the present study provide novel insights into the functional role of miR-376c-3p and suggest new approaches for the treatment of neuroblastoma.

\section{Introduction}

Neuroblastoma is the most common childhood malignancy derived from the primitive cells of the sympathetic nervous system (1). It accounts for $\sim 15 \%$ of all pediatric oncology deaths (2). The treatment of patients with advanced neuroblastoma or high-risk neuroblastoma is still a challenge due to several factors including, dose-limiting toxicity to standard chemotherapeutic agents, disease heterogeneity and tumor regression (3). Moreover, these patients have a very poor prognosis with the overall ten-year survival rates of less than $10 \%$ (4). Therefore, the development of innovate alternate treatment strategies is necessary to increase the treatment effectiveness and lower toxicity.

MicroRNAs (miRNAs/miRs) are a large family of small ( 22-25 nucleotides), endogenous, non-coding RNAs, which binds the partial or perfect complementary sequences in the 3'untranslated region (3'UTR) of target messenger RNAs (mRNAs) leading to translational repression or mRNA degradation (5). They regulate the expression of genes involved in proliferation, apoptosis, development and stress response. Thus, miRNAs have shown to play an important role in the initiation and progression of cancer (5). Depending on their respective target, miRNAs can act as oncogenes and or tumor suppressors (6). miRNAs are differentially expressed across cancer types and microRNA-profiling studies have revealed a general downregulation in tumors as compared with normal tissues (7). Interestingly, growing evidence have now shown the potential of aberrant expression of miRNAs to use as the prognostic and diagnostic biomarkers of human malignancies (6).

miR-376 family of miRNAs comprises of miR-376a2, $m i R-376 b, m i R-376 c$ (earlier known as $m i R-368$ ), $m i R-376 b 1$ and $m i R-376 b 2$ and their sequence identity is highly similar to mouse $m i R-376 a-c$ miRNAs (8). miR-376 family members are located on chromosome 14 in humans and at the distal end of mouse chromosome 12 (9). They are expressed in 
placenta, developing embryos, and adult tissues (8). The expression of $m i R-376 c$ is downregulated in many human malignancies including cervical cancer (10), prostate cancer (11), oral squamous cell carcinoma (12), intrahepatic cholangiocarcinoma (13), melanoma (14), osteosarcoma (15) and gliomas (16). However, it has been shown that $m i R-376 c$ is upregulated and it act as oncogenic in acute myeloid leukemia (17) and gastric cancer (18). In addition, forced expression of $m i R-376 c$ enhance ovarian cancer cell survival by targeting activing-receptor like kinase 7 (19). Whereas, forced overexpression of $m i R-376 c$ suppressed growth and invasion of non-small cell lung cancer (20). According to our knowledge, there is no report regarding the role of $m i R-376 \mathrm{c}$ in neuroblastoma. Thus uncovering the mechanisms of $m i R-376 c$ function is critical to both the fundamental understanding of neuroblastoma pathogenesis and novel therapeutic treatments.

The Cyclin D1 (CCNDI) is one of the extensively documented oncogene in human cancers. Functionally, CCNDI binds with cyclin-dependent kinases (CDK 4/6) which phosphorylate pRB family proteins, which in turn transactivates genes necessary for cell cycle progression (21). Dysregulated expression of $C C N D 1$ is a common feature in various human cancers $(22,23)$. Inhibitors targeting $C C N D 1$ are thoroughly studied but no results have yet been proven effective $(22,23)$. The CCND1 gene has one of the longest 3'UTR $(\sim 3.1 \mathrm{~kb})$, suggesting a strong functional relevance (24). To date, many experimentally validated miRNAs targeting $C C N D 1$ in different cancers are identified. For example, let-7e, $m i R-9-5 p$, miR-15a-5p, miR-16, miR-17, miR-20a, miR-106b, miR-34a and $m i R-206$ (25-31). However, no miRNA directly targeting CCND1 3'UTR is yet identified in neuroblastoma.

In this study, we examined the relationship between $m i R-376 c-3 p$ expression and neuroblastoma tumorigenesis. In our previous deep sequencing study, we have analyzed $m i R-376 c-3 p$ expression in neuroblastoma cell lines with different genetic characteristics (32). $m i R-376 c-3 p$ was downregulated in most of the cell lines tested and therefore we overexpressed $m i R-376 c-3 p$, which have had significant effects on cell growth and survival of neuroblastoma cells.

In addition, we demonstrated that $C C N D 1$ is a direct target of $m i R-376 c-3 p$ in neuroblastoma and overexpression of $m i R-376 c-3 p$ might have a significant influence on inhibition of neuroblastoma tumorigenesis.

\section{Materials and methods}

Cell culture. Human neuroblastoma cell lines, CHLA-15 and CHLA-20 were cultivated in Iscove's Modified Dulbecco's Medium (Sigma-Aldrich; Merck KGaA, Darmstadt, Germany) supplemented with $20 \%$ fetal bovine serum, $4 \mathrm{mM}$ L-Glutamine and 1X ITS $(5 \mu \mathrm{g} / \mathrm{ml}$ insulin, $5 \mu \mathrm{g} / \mathrm{ml}$ transferrin, and $5 \mathrm{ng} / \mathrm{ml}$ selenous acid). CHLA-15 and CHLA-20 were obtained from the same neuroblastoma patient prior to and following treatment with combination chemotherapy regimens, respectively. SKNAS, BE(2)-C, Kelly and SHSY-5Y cells were grown in RPMI-1640 medium (Sigma-Aldrich; Merck KGaA) supplemented with $10 \%$ fetal bovine serum and $2 \mathrm{mM}$ L-Glutamine (final concentrations). All cells were split before confluence and maintained at $37^{\circ} \mathrm{C}$ in a humidified incubator with 4.5 to $5 \% \mathrm{CO}_{2}$ atmosphere. The cell lines were authenticated by short tandem repeat profiling at the Center of Forensic Genetics, The Arctic University of Norway-UiT, Norway and tested negative for mycoplasma contamination. CHLA-15 and CHLA-20 cell lines were kindly provided by Children's Oncology Group, Cell Culture and Xenograft Repository, Texas Tech University Health Science Centre (Lubbock, TX, USA). BE(2)-C, SKNAS, Kelly and SHSY-5Y were provided by Dr. John Inge Johnsen (Childhood Cancer Research Unit, Department of Women's and Children's Health, Karolinska Institutet, Stockholm, Sweden).

Transfections. MicroRNA miR-376c-3p mimics or negative control (NC) mimics were purchased from GenePharma Co., Ltd. (Shanghai, China) and Ambion (Thermo Fisher Scientific, Inc., Waltham, MA, USA). Transfections of miRNA and NC mimics (25-40 nM) were carried out using Lipofectamine ${ }^{\circledR} 2000$ reagent (Thermo Fisher Scientific, Inc.) according to manufacturer's instructions.

Cell viability assay. CHLA-15, CHLA-20, BE(2)-C, Kelly and SHSY-5Y cells were seeded in 24-well plates and reverse transfected with $25 \mathrm{nM} m i R-376 c-3 p$ or NC mimics using Lipofectamine ${ }^{\circledR} 2000$ reagent (Thermo Fisher Scientific, Inc.). Every $24 \mathrm{~h}$ post-transfection, alamarBlue ${ }^{\circledR}$ (Thermo Fisher Scientific, Inc.) cell viability assay was performed according to manufacturer's instructions. Ten percent of the alamarBlue reagent was added to the cultured cells, mixed gently and incubated at $37^{\circ} \mathrm{C}$ for three hours. $100 \mu \mathrm{l}$ of medium was then transferred to black-walled 96-well plate and fluorescence was monitored at $540 \mathrm{~nm}$ excitation wavelength and $590 \mathrm{~nm}$ emission wavelength in a microplate reader (CLARIOstar; BMG Labtech GmbH, Offenburg, Germany). Cell viability was calculated as the percentage of NC transfected cells set to 100 percent.

Flow cytometric analysis of cell cycle distribution. The BE(2)-C, Kelly and SHSY-5Y cells were seeded in $25 \mathrm{~cm}^{2}$ culture flasks and reverse transfected with $25 \mathrm{nM}$ mimics as described previously. $24 \mathrm{~h}$ post-transfection cells were trypsinized and washed with $1 \mathrm{X}$ phosphate-buffered saline (PBS). The cells were then fixed in ice-cold $70 \%$ ethanol and incubated overnight at $-20^{\circ} \mathrm{C}$. Next day, the ethanol fixed cells were centrifuged for $10 \mathrm{~min}$ at $0.8 \mathrm{x} \mathrm{g}$ and washed twice with $1 \mathrm{X}$ PBS and resuspended in the propidium iodide (PI) (Thermo Fisher Scientific, Inc.) staining solution (PBS with $100 \mu \mathrm{g} / \mathrm{ml}$ RNase, $50 \mu \mathrm{g} / \mathrm{ml} \mathrm{PI}$ ). The cells were then incubated for $30 \mathrm{~min}$ protected from light and stored on ice until analyzed. Fluorescence emitted from the PI-DNA complex was analyzed by flow cytometry using BD LSRFortessa ${ }^{\mathrm{TM}}$ cell analyzer (BD Biosciences, Franklin Lakes, NJ, USA). FlowJo 7.6.5 software was used to analyze the cell cycle data using the Dean-Jett-Fox model for cell cycle evaluation.

Bioinformatics target prediction. TargetScan (version 6.2; www.targetscan.org/) target prediction software was used to predict miR-376c-3p targets related to cell cycle.

Reverse transcription-quantitative polymerase chain reaction (RT-qPCR).The Kelly, SHSY-5Y andBE(2)-C cells were seeded in 6-well plates and transfected with $40 \mathrm{nM}$ of $m i R-376 c-3 p$ or 
$\mathrm{NC}$ mimics. Cells were harvested $48 \mathrm{~h}$ post-transfection and total RNA was isolated with QIAzol ${ }^{\circledR}$ Lysis reagent (Qiagen Sciences, Inc., Gaithersburg, MD, USA) according to manufacturer's instructions and quantified by NanoDrop ${ }^{\text {TM }} 1000$ spectrophotometer (Thermo Fisher Scientific, Inc.).

For miRNA expression analysis, complementary DNA (cDNA) was synthesized from isolated total RNAs using the miScript II RT kit (Qiagen Sciences, Inc.) according to manufacturer's instructions. The reaction mixture (1X) $(20 \mu 1$ reaction volume) for reverse transcription was as follows: Total RNA, $1 \mu \mathrm{g}$ (diluted in RNase Free Water up to $12 \mu \mathrm{l}$ ); $5 \mathrm{X}$ miScript HiSpec Buffer, $4 \mu \mathrm{l}$; 10X miScript Nucleics Mix, $2 \mu \mathrm{l}$; miScript Reverse Transcriptase Mix, $2 \mu \mathrm{l}$; The cycling conditions were $37^{\circ} \mathrm{C}$ for $60 \mathrm{~min}$ followed by $95^{\circ} \mathrm{C}$ for $5 \mathrm{~min}$. The cDNA obtained was diluted with $80 \mu \mathrm{l}$ RNase Free Water to achieve $10 \mathrm{ng} / \mu \mathrm{l}$ concentration and stored at $-20^{\circ} \mathrm{C}$ until use. To quantitate $m i R-376 c-3 p$ levels, quantitative polymerase chain reaction was performed with miScript primer assay for miR-376c (cat. no MS00004046) using miScript SYBR ${ }^{\circledR}$ Green PCR kit (Qiagen Sciences, Inc.). The miScript primer assay for miR-4286 (cat. no MS00021371) was used as an internal control for normalization. The reaction mixture (1X) (20 $\mu \mathrm{l}$ reaction volume) for real time PCR was as follows: cDNA (1 ng/5 $\mu \mathrm{l}), 5 \mu \mathrm{l}$; QuantiTect SYBR-Green PCR Master Mix, $10 \mu \mathrm{l}$; Specific miScript primer assay, $2 \mu \mathrm{l}$; 10X miScript Universal Primer, $2 \mu \mathrm{l}$; RNase Free Water, $1 \mu 1$.

For basic miRNA expression levels in neuroblastoma cell lines, the following method was used for calculations. Raw fluorescence values (non-baseline corrected) generated from RT-qPCR reactions were used to calculate mean PCR efficiencies in the LinRegPCR software (Version 11.0; http://LinRegPCR.HFRC.nl.). N0 values (starting concentrations calculated by LinRegPCR software, $\mathrm{N} 0=$ threshold/ (mean amplicon efficiency ${ }^{\mathrm{Cq}}$ )) were used to calculate the expression of $m i R-376 c-3 p$ relative to the stably expressed miR-4286 (32). qPCR reactions were performed in triplicates on 2 independent biological replicates. Standard deviations were calculated taking into account the principle of error propagation (including technical and biological replicates).

For mRNA expression analysis, complementary DNA (cDNA) was synthesized from isolated total RNAs using the maxima reverse transcriptase (Thermo Fisher Scientific, Inc.) according to manufacturer's instructions. The reaction mixture (1X) (20 $\mu 1$ reaction volume) for reverse transcription of mRNAs was as follows: Oligo DT primer $(20 \mu \mathrm{M}), 1 \mu \mathrm{l}$; dNTP (10 mM each), $1 \mu \mathrm{l}$; Total RNA, $1 \mu \mathrm{g}$ (diluted in RNase Free Water up to $13.75 \mu \mathrm{l}$ ); Incubate $65^{\circ} \mathrm{C}$ for $5 \mathrm{~min}$ followed by addition of 5x RT Buffer, $4 \mu \mathrm{l}$; Maxima Reverse Transcriptase, $0.25 \mu \mathrm{l}$; The cycling conditions were $60^{\circ} \mathrm{C}$ for $30 \mathrm{~min}$ followed by $85^{\circ} \mathrm{C}$ for $5 \mathrm{~min}$. The cDNA obtained was diluted with $80 \mu \mathrm{l}$ RNase Free Water to achieve $10 \mathrm{ng} / \mu \mathrm{l}$ concentration and stored at $-20^{\circ} \mathrm{C}$ until use. To quantitate $C C N D 1$ levels, quantitative polymerase chain reaction was performed with Power SYBR-Green PCR Master Mix (Thermo Fisher Scientific, Inc.). SDHA housekeeping gene was used as an internal control for normalization. The reaction mixture (1X) $(20 \mu 1$ reaction volume) for real time PCR was as follows: cDNA (1 ng/1 $\mu \mathrm{l})$, $10 \mu \mathrm{l}$; Power SYBR-Green PCR Master Mix, $5 \mu \mathrm{l}$; Forward
Primer $(10 \mu \mathrm{M}), 0.4 \mu \mathrm{l}$; Reverse Primer $(10 \mu \mathrm{M}), 0.4 \mu \mathrm{l}$; RNase Free Water $4.2 \mu 1$.

Amplifications were carried out using Light Cycler 96 SW 1.1 (Roche Diagnostics GmbH, Mannheim, Germany) and expression levels of miRNAs and mRNAs were evaluated using the comparative $\Delta \Delta \mathrm{Cq}$ comparative cycle threshold method (33). The primers used were $C C N D 1$ (forward: 5'-CCGTCCATG CGGAAGATC-3'; reverse: 5'-ATGGCCAGCGGGAAGAC-3') and SDHA (forward: 5'-CTGATGAGACAAGATGTGGTG-3'; reverse: 5'-CAATCTCCCTTCAATGTACTCC-3').

Western blot analysis. Cells were trypsinized and lysed in $40 \mu 1$ RIPA buffer (50 mM Tris-HCL pH 8, $150 \mathrm{mM} \mathrm{NaCl}, 1 \%$ NP-40, $0.5 \%$ sodium deoxycholate, $0.1 \%$ SDS) supplemented with 1X Protein Inhibitor Cocktail (Roche Diagnostics $\mathrm{GmbH}$ ) and $1 \mathrm{mM}$ dithiothreitol (DTT). Lysate was cleared with centrifugation $(21.1 \mathrm{x} \mathrm{g})$ and the total protein concentrations were determined using DC ${ }^{\mathrm{TM}}$ Protein Assay kit (Bio-Rad Laboratories, Inc., Hercules, CA, USA) according to manufacturer's instructions. $40 \mu \mathrm{g}$ protein was then loaded in each well and separated on a NuPAGE ${ }^{\circledR}$ Novex $4-12 \%$ Bis-Tris precast polyacrylamide gel (Thermo Fisher Scientific, Inc.). The separated proteins were transferred on Immobilon-FL PVDF membrane (EMD Millipore, Billerica, MA, USA) and blocked for $1 \mathrm{~h}$ at room temperature in $5 \mathrm{ml}$ Odyssey Blocking Buffer (LI-COR Biosciences, Lincoln, NE, USA). The PVDF membrane was then incubated overnight at $4^{\circ} \mathrm{C}$ with primary antibodies anti-Cyclin D1-(H-295)-Human Cyclin D1 Rabbit, polyclonal; (1:1,000; Santa Cruz Biotechnology, Inc., Dallas, TX, USA) and anti-actin-(ab3280)-Human Actin Mouse, monoclonal (1:1,000; Abcam, Cambridge, UK). The secondary antibodies used were goat anti-rabbit-IRDye $80^{\circ \mathrm{C}} \mathrm{W},(1: 5,000)$ (Rockland Immunochemicals, Inc., Gilbertsville, PA, USA) and goat anti-mouse-Alexa Fluor 680, (1:5,000; Thermo Fisher Scientific, Inc.). Antibody binding was detected using the Odyssey CLx Infrared Imaging System (LI-COR Biosciences). ImageJ software was used to quantify western blot results.

Luciferase reporter assay. The pMIR-Report-Cyclin D1-UTR-WT construct was a generous gift from Dr. Laura Barkley (30) and pMIR-Report-Cyclin D1-UTR-MUT construct with a mutation in the putative $m i R-376 c-3 p$ seed sequence (mutant) was generated using QuikChange ${ }^{\circledR}$ Multi Site-Directed Mutagenesis kit (Agilent Technologies, Inc., Santa Clara, CA, USA). The primers used for mutagenesis were CCND1_3'UTR_miR-376c-3p (forward: 5'-CACATC TTGGCATACTAATTCTTG-3'; reverse: 5'-CAAGAATTA GTATGCCAAGATGTG-3'). To validate for mutation in seed sequence the mutant plasmid was sequenced using sequencing primer 5'-CATCTGATTGGACAGGCATG-3'. The cells seeded at a density of $5 \times 10^{4}$ cells/well in a 12 -well plate were co-transfected with $40 \mathrm{nM} \mathrm{NC}$ or $m i R-376 c-3 p$ mimics, $20 \mathrm{ng}$ pRL-SV40 construct (Promega Corporation, Madison, WI, USA) and $100 \mathrm{ng}$ wild type or mutant luciferase constructs using Lipofectamine ${ }^{\circledR} 2000$ reagent (Thermo Fisher Scientific, Inc.). $24 \mathrm{~h}$ post-transfection, firefly and renilla luciferase activities analyzed using the Dual-Luciferase Reporter Assay (Promega Corporation), according to manufacturer's instructions. Firefly luciferase activity was normalized against renilla luciferase 
activity and luciferase activities of $m i R-376 c-3 p$ transfected cells were calculated relative to $\mathrm{NC}$ transfected cells set to $100 \%$.

MicroRNA expression data from neuroblastoma tumors. miRNA expression data from 226 primary neuroblastoma tumors were obtained through the Neuroblastoma Research Consortium (NRC). Differential miRNA expression was analyzed using a Kruskal-Wallis test.

Statistical analysis. The data was expressed as mean \pm standard deviation (SD). Unless otherwise stated, all experiments were performed at least three times independently. Statistical analysis was performed using the software GraphPad Prism version 5.00 for Windows (GraphPad Software, Inc., La Jolla, CA, USA; available at www.graphpad.com). Statistical differences between means were determined using Student's t-test. $\mathrm{P}<0.05$ was considered to indicate a statistically significant difference.

\section{Results}

Multiple miRNAs located at $14 q 32$ chromosomal region are downregulated and their lower levels are associated with poor prognosis factors in neuroblastoma. Results from our previous study, where we used next generation sequencing technology (SOLiD ligation sequencing) to determine miRNA expression profiles in neuroblastoma cell lines established from patients at diagnosis and at relapse after treatment, identified 22 downregulated microRNAs from 14q32 miRNA cluster. The expression of these downregulated miRNAs was confirmed in a cohort consisting of 226 primary neuroblastomas (32). $m i R-376 c-3 p$, was one of the 22 miRNAs that was downregulated in most of the cell lines isolated from patients after the treatment (Fig. 1A). When miR-376c expression was compared in neuroblastoma primary tumors of different stages from the 226-cohort, we observed a trend towards lower expression in advanced stage disease compared to tumors in stage 1 (Fig. 1B). Thus, we sought out to focus on the functional role of $m i R-376 c-3 p$ in neuroblastoma.

miR-376c-3p reduces cell viability in neuroblastoma cell lines. Even though $m i R-376 c-3 p$ has been shown to play either the oncogenic or the tumor suppressive role in different cancers (10-20) the functional role of $m i R-376 c-3 p$ is not yet determined in neuroblastoma. Therefore, we first used RT-qPCR to measure miR-376c-3p basic expression levels relative to $m i R-4286$ in 6 neuroblastoma cell lines. $m i R-4286$ was previously showed to be stably expressed in neuroblastoma cell lines (32). Among the cell lines, SKNAS and BE(2)-C cells have the highest expression level of $m i R-376 c-3 p$, whereas SHSY-5Y, Kelly, CHLA-15 and CHLA-20 cells showed barely detectable levels of expression (Fig. 2A). In order to find out the potential role of $m i R-376 c-3 p$ in neuroblastoma, cell viability assay was performed on several neuroblastoma cell lines by overexpressing NC or $m i R-376 c-3 p$ mimics. The expression of $m i R-376 c-3 p$ was significantly increased in $m i R-376 c-3 p$ transfected cell lines compared with NC transfected cells, as validated and confirmed by RT-qPCR (Fig. 2B). Cell viability alamarBlue assay was performed at 24, 48, 72 and $96 \mathrm{~h}$ post-transfection, which showed that neuroblastoma cell

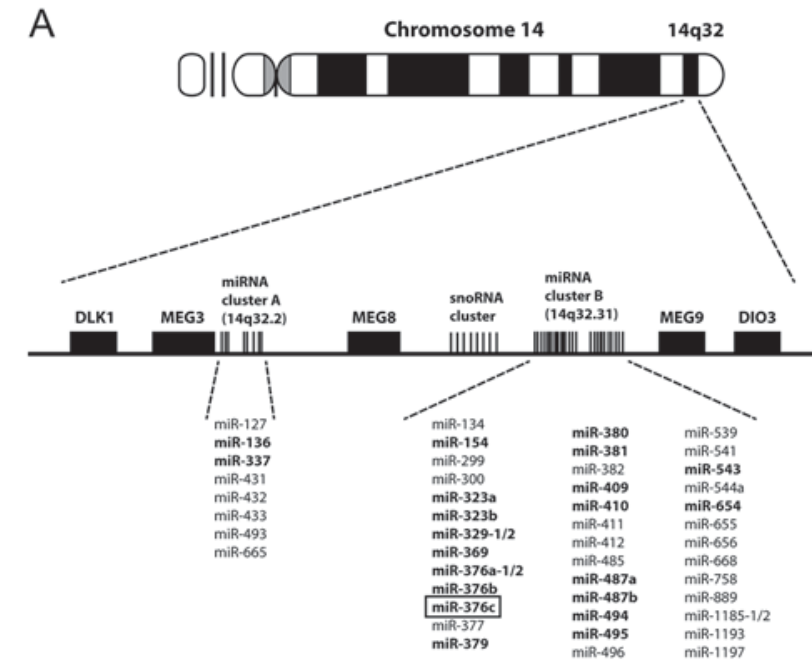

B

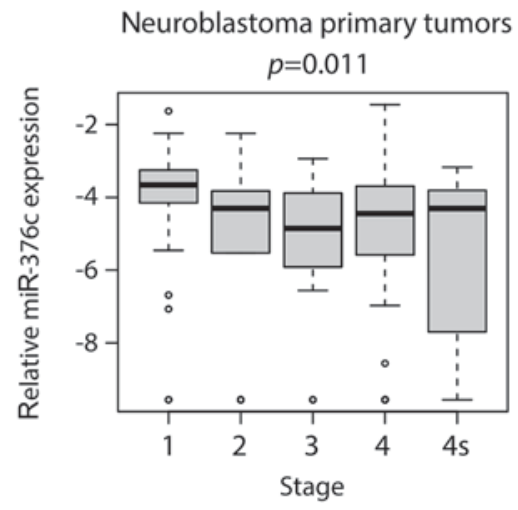

Figure 1. (A) Schematic representation of the miRNA-cluster at $14 \mathrm{q} 32$ chromosomal region. Multiple miRNAs located at 14q32 chromosomal region are downregulated (bold type) and associated with poor prognosis factors in neuroblastoma. The miRNA of interest, miR-376c-3p is shown in bold and a rectangular box. (B) Box-plots of miR-376c expression in tumors from neuroblastoma patients at different stages. The boxes represent the $25-75 \%$ quartiles. The horizontal line in the boxes represents the median level. Whiskers represent the non-outlier range. Open circles represent the outliers. $\mathrm{P}=0.011$, comparing the median expression level of miR376c-3p across all pathological stages. DLK1, Delta Like Non-canonical Notch Ligand 1; MEG, maternally expressed; snoRNA, small nucleolar RNAs; DIO3, iodothyronine deiodinase 3 ; miR/miRNA, microRNA.

lines transfected with $m i R-376 c-3 p$ mimics, had significantly reduced cell viability as compared to NC transfected cells. Thus, ectopic expression of $m i R-376 c-3 p$ reduced the growth of SKNAS, CHLA-15, CHLA-20, SHSY-5Y, Kelly and BE(2)-C cells as compared to NC transfected cells (Fig. 2C). These results indicate that cell growth of neuroblastoma cell lines is significantly affected by overexpression of $m i R-376 c-3 p$.

miR-376c-3p induces a G1-cell cycle arrest in neuroblastoma cells. We did not detect significant apoptosis in $m i R-376 c-3 p$ transfected neuroblastoma cells using Annexin V and PARP cleavage assay (data not shown). Thus, we investigated the effects of $m i R-376 c-3 p$ overexpression on cell cycle distribution of representative neuroblastoma cell lines BE(2)-C, Kelly and SHSY-5Y by flow cytometric assay. Ectopic expression of $m i R-376 c-3 p$ in BE(2)-C, Kelly and SHSY-5Y resulted in increased percentage of cells in G1-phase of cell cycle as compared to $\mathrm{NC}$ transfected cells by $13 \%\left({ }^{* *} \mathrm{P}=0.0023\right)$, 

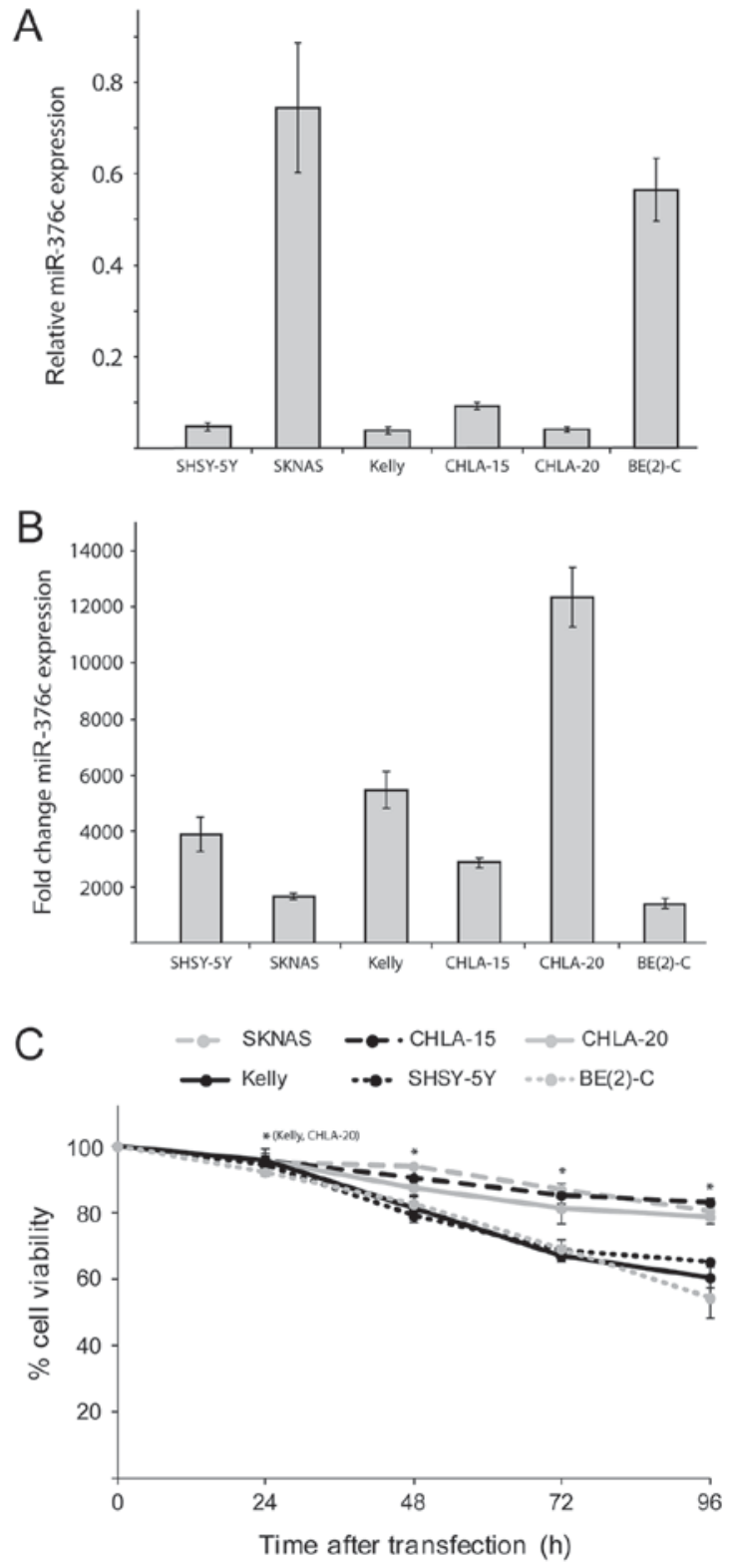

Figure 2. miR-376c-3p reduces cell viability in neuroblastoma cell lines. (A) RT-qPCR analysis was performed to quantitate the basic expression of $m i R-376 c-3 p$ in 6-neuroblastoma cell lines. $m i R-4286$ served as an endogenous control for miRNAs. Error bars indicate mean \pm SD of two independent experiments, each repeated in triplicate. (B) RT-qPCR analysis for confirmation of $m i R-376 c-3 p$ overexpression in 6-neuroblastoma cell lines transfected with NC or $m i R-376 c-3 p$ mimics. Expression of $m i R-376 c-3 p$ in SHSY-5Y cell line was set to 1 and $m i R-4286$ served as an endogenous control for miRNAs. Error bars indicate mean \pm SD. of two independent experiments, each repeated in triplicates. (C) Cell growth analysis of neuroblastoma cells transfected with NC or $m i R-376 c-3 p$ mimics. BE(2)-C, Kelly and SHSY-5Y were more sensitive compared with SKNAS, CHLA-15 and CHLA-20. Error bars indicate mean \pm SD of three independent experiments repeated in triplicate. The results were statistically significant at 48,72 and $96 \mathrm{~h}$ for all cell lines. ${ }^{*} \mathrm{P}<0.05$. RT-qPCR, reverse transcription-quantitative polymerase chain reaction; NC, negative control; SD, standard deviation; miR, microRNA.

$16 \%\left({ }^{* * *} \mathrm{P}=0.0001\right)$ and $9 \%\left({ }^{*} \mathrm{P}=0.0106\right)$, respectively with a corresponding reduction in the percentage of cells in the $\mathrm{S}$ and G2/M-phase (Fig. 3). Thus, this observation led us to the conclusion that decrease in cell viability might be due to induction of G1-cell cycle arrest in neuroblastoma cells and not apoptosis.
CCND1 is a direct target of miR-376c-3p in neuroblastoma. In order to investigate the underlying molecular mechanisms of $m i R-376 c-3 p$ induced suppression of the cell viability and G1-cell cycle arrest, a bioinformatics analysis was performed using miRNA target prediction algorithm TargetScan (Release 6.2; www.targetscan.org/) to predict the target genes of $m i R-376 c$-3p mainly associated with the cell cycle progression. TargetScan revealed 254 potential downstream targets with the conserved sites for $m i R-376 c-3 p$ (data not shown). It was theoretically demonstrated that $m i R-376 c-3 p$ had single binding site in the 3'UTR of CCNDI oncogene. Thus, to determine whether $m i R-376 c-3 p$ could directly target the predicted 3'UTR of $C C N D 1$, a dual-luciferase reporter assay was performed in BE(2)-C and SHSY-5Y cells. Here, we used a luciferase reporter containing full-length $(\sim 3.1 \mathrm{~kb})$, wild type CCND1 3'UTR (wt) or mutant CCND1 3'UTR (MUT) construct having a mutation of the putative $m i R-376 c-3 p$ target site shown in bold and italics (Fig. 4A).

Transient co-transfection of BE(2)-C and SHSY-5Y cells with $m i R-376 c-3 p$ mimics and the wild type CCND1 3'UTR (wt) reporter construct suppressed the luciferase activity as compared to $\mathrm{NC}$ transfected cells by $35 \%\left({ }^{* *} \mathrm{P}=0.0091\right)$ and $38 \%\left({ }^{*} \mathrm{P}=0.0135\right)$, respectively. However, the activity of the reporter construct mutated at the specific $m i R-376 c-3 p$ target site is unaffected (Fig. 4B). These data indicated that $m i R-376 c-3 p$ represses $C C N D 1$ expression by directly binding to the 3'UTR sequence of CCNDI mRNA.

miR-376c-3p reduces $m R N A$ and protein levels of CCND1 in neuroblastoma cells. To further confirm whether $m i R-376 c-3 p$ directly targets $C C N D 1$ gene, neuroblastoma cells were transfected with $m i R-376 c-3 p$ or NC mimics and the expression levels of $C C N D 1$ was analyzed by quantitative RT-qPCR analysis. The levels of CCND1 mRNA was markedly decreased by $m i R-376 c-3 p$ overexpression in BE2-(C), Kelly and SHSY-5Y cells by $57 \%\left({ }^{*} \mathrm{P}=0.0110\right), 57 \%\left({ }^{* *} \mathrm{P}=0.0017\right)$, and $53 \%\left({ }^{*} \mathrm{P}=0.0134\right)$, respectively as compared to NC transfected cells (Fig. 5A). Moreover, we also performed western blot analysis and observed significant decrease in levels of cyclin D1 proteins upon $m i R-376 c-3 p$ overexpression in BE2-(C), Kelly and SHSY-5Y cells by $41 \%\left({ }^{* *} \mathrm{P}=0.0089\right), 67 \%$ ( $\left.{ }^{* *} \mathrm{P}=0.0032\right)$, and $69 \%\left({ }^{* *} \mathrm{P}=0.0069\right)$, respectively as compared to NC transfected cells (Fig. 5B and C). Taken together, these results demonstrates that endogenous expression of CCND1 gene is directly regulated by $m i R-376 c-3 p$ and suggest that overexpression of $C C N D 1$ gene could be reduced by enforced expression of $m i R-376 c-3 p$ in neuroblastoma cells.

In addition, to test whether $C C N D 1$ could also counteract the effect of $m i R-376 c-3 p$ induced G1 cell cycle arrest, we overexpressed CCND1 in SHSY-5Y cells. However, we only saw a modest and statistically insignificant effect of CCND1 overexpression on reducing the effect of miR-376c-3p (Fig. 6).

\section{Discussion}

Current treatment strategies for high-risk neuroblastoma patients have limitations due to the refractory nature of the disease (2-4). Hence, alternative strategies are necessary for diagnosis and treatment of this disease. Mounting evidence have shown the potential of miRNAs as key regulators of 


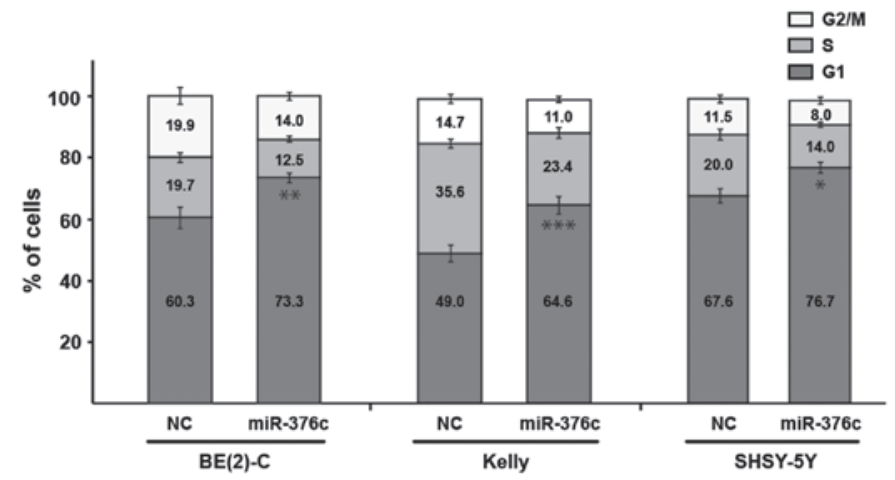

Figure 3. $m i R-376 c-3 p$ induces G1-cell cycle arrest in neuroblastoma cells. BE(2)-C, Kelly and SHSY-5Y cells were transfected with NC or $m i R-376 c-3 p$ mimics and the cell cycle analysis was evaluated by a propidium iodide-flow cytometric assay. The percentage of G1-arrested cells increased after $m i R-376 c-3 p$ overexpression. Error bars indicate mean \pm standard deviation of three independent experiments repeated in triplicates. NC, negative control; miR, microRNA ${ }^{*} \mathrm{P}<0.05,{ }^{* *} \mathrm{P}<0.01$ and ${ }^{* * *} \mathrm{P}<0.001$ vs. NC.
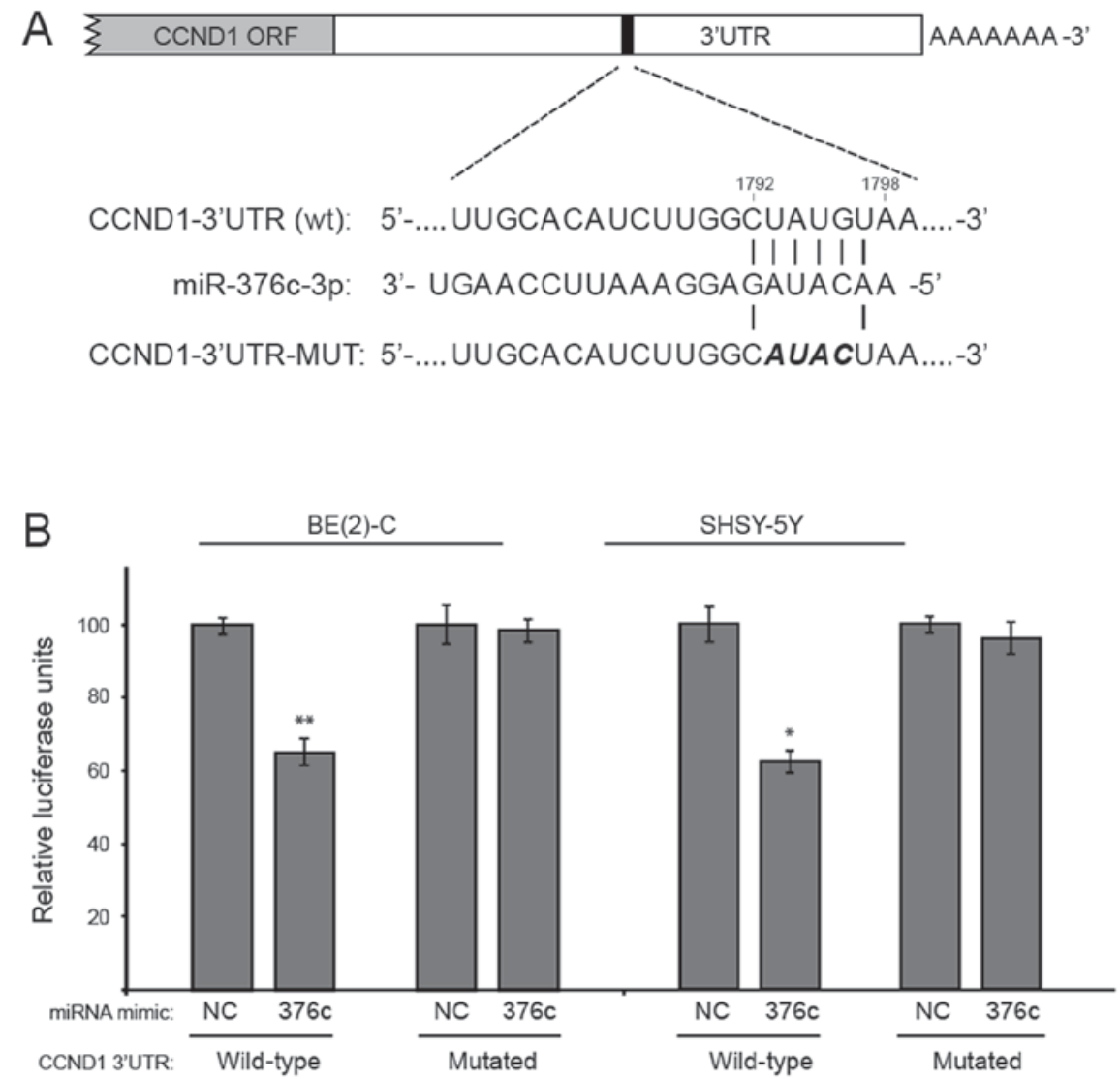

Figure 4. $C C N D 1$ is a direct target of $m i R-376 c-3 p$ in neuroblastoma. (A) The $C C N D 1$ 3'UTR contain one predicted $m i R-376 c-3 p$ binding site (nucleotides 1,792 to 1,798). In the figure, the alignment of the seed region of $m i R-376 c-3 p$ with CCND1 and the site of target mutagenesis are shown in bold and italics. (B) pMIR-Report-CCND1 luciferase constructs containing a full-length wt or mutated CCND1 3'UTR and $m i R-376 c-3 p$ or NC mimics, were co-transfected into BE(2)-C and SHSY-5Y cells. Luciferase activity of wt construct was significantly reduced compared with mutated constructs. Relative repression of firefly luciferase activity is normalized with renilla luciferase activity. Error bars indicate mean \pm standard devaition of three independent experiments repeated in triplicates. "P $<0.05,{ }^{* *} \mathrm{P}<0.01$ vs. the adjacent NC. miR, microRNA; NC, negative control; CCND1, cyclin D1; ORF, open reading frame; UTR, untranslated region; wt, wild type; MUT, mutated.

cancer pathogenesis by acting as oncogenes or tumor suppressors (6). Researchers have thus exploited these properties for the development of the novel anticancer therapies. miRNAs act by inhibiting the expression of its one or more target genes. Hence, identification of specific miRNAs and their targets is very important for the diagnosis and therapy of cancer (34).

Results from our previous deep sequencing analysis study identified 22 downregulated microRNAs from 14q32 miRNA cluster differentially expressed in neuroblastoma cell lines isolated from six patients at diagnosis and at relapse after intensive treatments. $m i R-376 c-3 p$, is one of the 22 miRNAs that was downregulated in most of the cell lines isolated from patients after treatment (32). Moreover, the expression of $m i R-376 c-3 p$ was reduced in International Neuroblastoma Staging System (INSS) stage 4 compared to stage 1-2 in a cohort of 226 primary neuroblastoma tumors (32). However, 
A

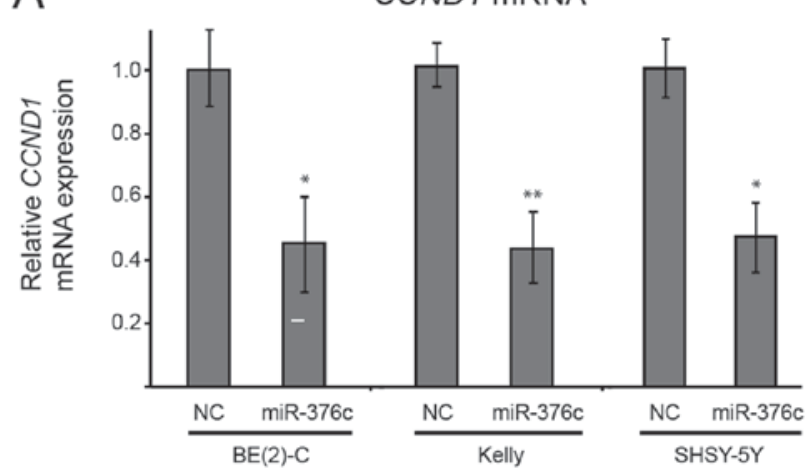

B

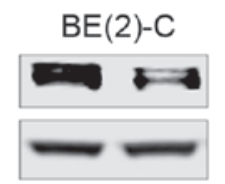

NC miR-376c
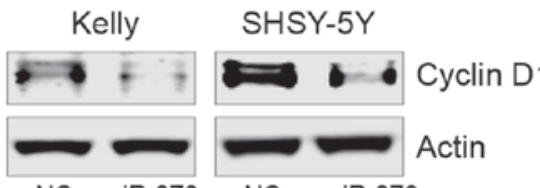

NC miR-376c NC miR-376c

C

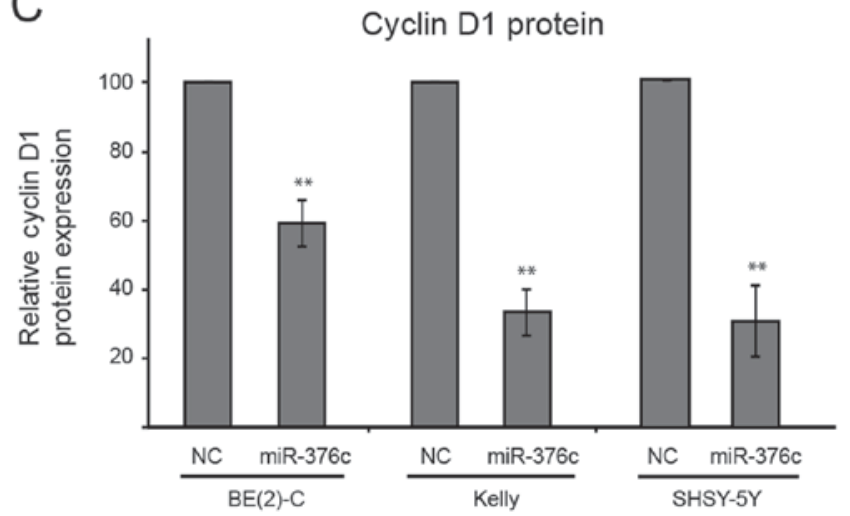

Figure 5. $m i R-376 c-3 p$ reduces mRNA and protein levels of CCND1 in neuroblastoma cells. (A) $m i R-376 c-3 p$ overexpression significantly decreases $C C N D 1$ mRNA levels in BE(2)-C, Kelly and SHSY-5Y. These cells were transfected with $\mathrm{NC}$ or $m i R-376 c-3 p$ mimics for $48 \mathrm{~h}$ and $C C N D 1$ levels were assessed by reverse transcription-quantitative polymerase chain reaction. (B) $m i R-376 c-3 p$ overexpression significantly decreases endogenous levels of Cyclin D1 proteins in BE(2)-C, Kelly and SHSY-5Y. These cells were transfected with NC or $m i R-376 c-3 p$ mimics for $96 \mathrm{~h}$ and Cyclin D expression assessed by western blot analysis. The $\beta$-actin antibody used as a loading control. (C) Quantitative analysis of Cyclin D1 protein expression on the western blots $(\mathrm{n}=3)$. Error bars indicate mean \pm standard deviation of three independent experiments. ${ }^{*} \mathrm{P}<0.05$ and ${ }^{* *} \mathrm{P}<0.01$ vs. the adjacent $\mathrm{NC}$ miR, microRNA; NC, negative control; CCND1, cyclin D1.

the functional role of $m i R-376 c-3 p$ in neuroblastoma is not yet established.

Earlier reports from various cancers have demonstrated the dual nature of $m i R-376 c-3 p$ to act as either the oncogenic or the tumor suppressive miRNA depending on the cellular contexts (10-20). $m i R-376 c-3 p$ is downregulated in multiple human cancers, including prostate cancer (11), cervical cancer (10), oral squamous cell carcinoma (12), intrahepatic cholangiocarcinoma (13), melanoma (14), osteosarcoma (15) and gliomas (16). In contrast, $m i R-376 c-3 p$ was upregulated in acute myeloid leukemia (17) and gastric cancer (18). In these cancers, $m i R-376-3 p$ has been shown to target a set of genes including B-cell-specific moloney murine leukemia virus insertion site 1 (BMI), homeobox B7 (HOXB7),

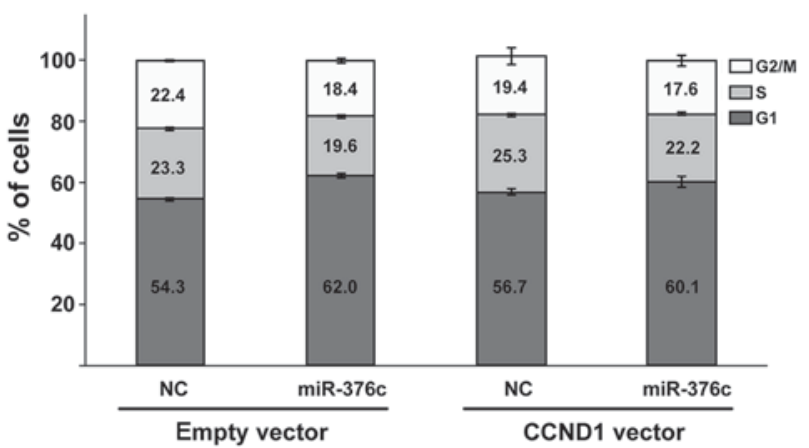

Figure 6. CCND1 overexpression partially rescues neuroblastoma cells from $m i R-376 c-3 p$ induced G1 cell cycle arrest. SHSY-5Y cells were co-transfected with NC or $m i R-376 c-3 p$ mimics and an empty or cyclin D1 overexpression plasmid. $96 \mathrm{~h}$ after the transfection, cells were ethanol fixed and cell cycle analysis was evaluated by the PI-flow cytometric assay. The results of the cell cycle analysis are depicted as percentage of cells in particular phases of cell cycle. Error bars indicate mean \pm standard deviation of at least three repeats miR, microRNA; NC, negative control; CCND1, cyclin D1.

growth factor receptor-bound protein 2 (GRB2), transforming growth factor-alpha (TGFA), liver receptor homolog-1 (LRH-1), insulin growth factor 1 receptor (IGF1R) and activin receptor-like kinase 7 (ALK7). Other than affecting cell growth and proliferation, these genes act as important mediators of cell invasion $(10,12,15,20)$, migration (11-14), cell cycle arrest (10), apoptosis (12) and chemoresistance (19).

In order to find out how miR-376c-3p affects the growth and viability of neuroblastoma cells we first performed alamarBlue cell viability assay and demonstrated that transient overexpression of $m i R-376 c-3 p$ resulted in inhibition of cell viability in neuroblastoma cell lines. Consistent with this finding, we also observed that $m i R-376 c-3 p$ induced G1-cell cycle arrest suggesting that cell cycle genes may be affected and could serve as $m i R-376 c-3 p$ targets. To test this hypothesis, we used miRNA bioinformatics algorithms to predict $m i R-376 c-3 p$ targets related to the cell cycle regulation. TargetScan algorithm predicted the $C C N D 1$ gene as a probable target of $m i R-376 c-3 p$. CCNDI is an important cell cycle regulator whose mRNA contains a conserved $m i R-376 c-3 p$ binding site on the 3'UTR. By dual-luciferase reporter assay, we further demonstrated that $m i R-376 c-3 p$ could significantly reduce luciferase activity of wild type constructs but not mutated CCND1 3'UTR construct confirming the direct regulation on $C C N D 1$ by $m i R-376 c-3 p$. Our experimental data further showed that the expression of CCND1 mRNA and protein levels were significantly reduced after transfection with $m i R-376 c-3 p$ mimics as compared to NC mimics transfected cells. Additionally, we also performed flow cytometric rescue experiment by overexpression of CCND1 in neuroblastoma cells to see if $C C N D 1$ counteracts the effect of $m i R-376 c-3 p$ induced G1 cell cycle arrest. However, we only saw a modest and statistically insignificant effect of $C C N D 1$ overexpression on reducing the effect of $m i R-376 c-3 p$ overexpression.

Cyclin D1, Cyclin D2 and Cyclin D3 belongs to the class of cyclins, which activates the cyclin-dependent kinases (CDKs). These cyclins through the phosphorylation of the substrates at specific cell stages co-ordinates the sequential completion of DNA replication and cell division (23). Unlike other cyclins, CCND1 is induced by extracellular signals, including 
growth factor receptor activation and integrin-derived adhesion signaling $(23,35)$. Functionally, CCND1 activates CDK4/6, which phosphorylates pRB family proteins causing the release of E2F transcription factors, which are essential for transcription of genes necessary for G1-S transition of cell cycle. Hence, the expression of cyclins are tightly regulated by variety of signaling pathways at the transcriptional as well as post-transcriptional levels (21).

The CCND1 gene has been proposed as an important oncogene in various cancers. Numerous studies have documented the relationship between deregulation of CCND1 and onset of tumorigenesis in wide variety of cancers. For instance, Molenaar et al $(36,37)$ found that $C C N D 1$ levels were increased in neuroblastoma tumors and high expression of $C C N D 1$ led to tumorigenesis in neuroblastoma. In addition, Rihani et al (22) found that knockdown of $C C N D 1$ reduced cell proliferation, induced G1-cell cycle arrest and inhibited the cyclin D1-Rb pathway in neuroblastoma cells. Similarly, Sun and colleagues also found that inhibition of CCND1 and CDK6 by $m i R-34 a$ resulted in G1-cell cycle arrest in non-small cell lung cancer (38). In line with these reports, our data indicate that ectopic expression of $m i R-376 c-3 p$ leads to the suppression of endogenous $C C N D 1$ gene resulting in the reduced cell growth and G1-cell cycle arrest in the neuroblastoma cells.

Taken together, our study for the first time demonstrates that miR-376c-3p directly target CCNDl gene leading to reduced cell growth and G1-cell cycle arrest in neuroblastoma. Therefore, we suggest that ' $m i R-376 c-C C N D 1$ ' axis could be a potential molecular target for preventing neuroblastoma tumorigenesis.

\section{Acknowledgements}

The authors would like to thank the Children's Oncology Group Cell Culture and Xenograft Repository (Texas Tech University Health Science Center, Lubbock, TX, USA) for providing the BE(2)-C, CHLA-15 and CHLA-20 cell lines, and Dr. Laura Barkley (National Centre for Biomedical Engineering Science, National University of Ireland Galway, Galway, Ireland) for providing the full-length CCND1 3'UTR construct (pMIR-Report-Cyclin D1-UTR-WT). The authors would also like to thank Professor Pieter Mestdagh (Ghent University, Ghent, Belgium) for providing the miRNA expression data from primary neuroblastoma tumors obtained through the Neuroblastoma Research Consortium initiative.

\section{Funding}

This work was supported by grants from the Northern-Norway Health Authorities (grant no. SFP 1278-16).

\section{Availability of data and materials}

All data generated or analyzed during this study are included in this published article.

\section{Author's contributions}

SPB, TF and CE designed the research. SPB performed the experiments. CL assisted with the experiments. CE, CL and
TF supervised the experimental work. SPB wrote the manuscript. CE, CL and TF critically amended the manuscript. The final manuscript was read and approved by all authors.

\section{Ethics approval and consent to participate}

Not applicable.

\section{Patient consent for publication}

Not applicable.

\section{Competing interests}

The authors declare that they have no competing interests.

\section{References}

1. Brodeur GM: Neuroblastoma: Biological insights into a clinical enigma. Nat Rev Cancer 3: 203-216, 2003.

2. Maris JM,Hogarty MD, Bagatell R and Cohn SL: Neuroblastoma. Lancet 369: 2106-2120, 2007

3. Garaventa A: High risk neuroblastoma: Small steps towards cure. Pediatr Blood Cancer 61: 964-965, 2014.

4. Garaventa A, Parodi S, De Bernardi B, Dau D, Manzitti C, Conte M, Casale F, Viscardi E, Bianchi M, D'Angelo P, et al: Outcome of children with neuroblastoma after progression or relapse. A retrospective study of the Italian neuroblastoma registry. Eur J Cancer 45: 2835-2842, 2009.

5. Croce CM and Calin GA: miRNAs, cancer, and stem cell division. Cell 122: 6-7, 2005.

6. Berindan-Neagoe I, Monroig Pdel C, Pasculli B and Calin GA: MicroRNAome genome: A treasure for cancer diagnosis and therapy. CA Cancer J Clin 64: 311-336, 2014.

7. Lu J, Getz G, Miska EA, Alvarez-Saavedra E, Lamb J, Peck D, Sweet-Cordero A, Ebert BL, Mak RH, Ferrando AA, et al: MicroRNA expression profiles classify human cancers. Nature 435: 834-838, 2005.

8. Kawahara Y, Zinshteyn B, Sethupathy P, Iizasa H, Hatzigeorgiou AG and Nishikura K: Redirection of silencing targets by adenosine-to-inosine editing of miRNAs. Science 315: 1137-1140, 2007.

9. Seitz H, Royo H, Bortolin ML, Lin SP, Ferguson-Smith AC and Cavaillé J: A large imprinted microRNA gene cluster at the mouse Dlk1-Gt12 domain. Genome Res 14: 1741-1748, 2004.

10. Deng Y, Xiong Y and Liu Y: miR-376c inhibits cervical cancer cell proliferation and invasion by targeting BMI1. Int J Exp Pathol 97: 257-265, 2016.

11. Formosa A, Markert EK, Lena AM, Italiano D, Finazzi-Agro' E, Levine AJ, Bernardini S, Garabadgiu AV, Melino G and Candi E: MicroRNAs, miR-154, miR-299-5p, miR-376a, miR-376c, miR-377, miR-381, miR-487b, miR-485-3p, miR-495 and miR-654-3p, mapped to the $14 q 32.31$ locus, regulate proliferation, apoptosis, migration and invasion in metastatic prostate cancer cells. Oncogene 33: 5173-5182, 2014.

12. Wang $\mathrm{K}$, Jin J, Ma $\mathrm{T}$ and Zhai $\mathrm{H}$ : $\mathrm{miR}-376 \mathrm{c}-3$ p regulates the proliferation, invasion, migration, cell cycle and apoptosis of human oral squamous cancer cells by suppressing HOXB7. Biomed Pharmacother 91: 517-525, 2017.

13. Iwaki J, Kikuchi K, Mizuguchi Y, Kawahigashi Y, Yoshida H, Uchida E and Takizawa T: miR-376c down-regulation accelerates EGF-dependent migration by targeting GRB2 in the HuCCT1 human intrahepatic cholangiocarcinoma cell line. PLoS One 8: e69496, 2013.

14. Zehavi L, Avraham R, Barzilai A, Bar-Ilan D, Navon R, Sidi Y, Avni D and Leibowitz-Amit R: Silencing of a large microRNA cluster on human chromosome 14q32 in melanoma: Biological effects of mir-376a and mir-376c on insulin growth factor 1 receptor. Mol Cancer 11: 44, 2012.

15. Jin Y, Peng D, Shen Y, Xu M, Liang Y, Xiao B and Lu J: MicroRNA-376c inhibits cell proliferation and invasion in osteosarcoma by targeting to transforming growth factor-alpha. DNA Cell Biol 32: 302-309, 2013. 
16. Huang Q, Wang C, Hou Z, Wang G, Lv J, Wang H, Yang J, Zhang $Z$ and Zhang H: Serum microRNA-376 family as diagnostic and prognostic markers in human gliomas. Cancer Biomark 19: 137-144, 2017.

17. Dixon-McIver A, East P, Mein CA, Cazier JB, Molloy G, Chaplin T, Andrew Lister T, Young BD and Debernardi S: Distinctive patterns of microRNA expression associated with karyotype in acute myeloid leukaemia. PLoS One 3: e2141, 2008

18. Shiotani A, Murao T, Kimura Y, Matsumoto H, Kamada T, Kusunoki $\mathrm{H}$, Inoue $\mathrm{K}$, Uedo $\mathrm{N}$, Iishi $\mathrm{H}$ and Haruma $\mathrm{K}$ : Identification of serum miRNAs as novel non-invasive biomarkers for detection of high risk for early gastric cancer. $\mathrm{Br}$ J Cancer 109: 2323-2330, 2013.

19. Ye G, Fu G, Cui S, Zhao S, Bernaudo S, Bai Y, Ding Y, Zhang Y, Yang BB and Peng C: MicroRNA 376c enhances ovarian cancer cell survival by targeting activin receptor-like kinase 7: Implications for chemoresistance. J Cell Sci 124: 359-368, 2011.

20. Jiang W, Tian Y, Jiang S, Liu S, Zhao X and Tian D MicroRNA-376c suppresses non-small-cell lung cancer cell growth and invasion by targeting LRH-1-mediated Wnt signaling pathway. Biochem Biophys Res Commun 473: 980-986, 2016.

21. Arand J and Sage J: G1 cyclins protect pluripotency. Nat Cell Biol 19: 149-150, 2017.

22. Rihani A, Vandesompele J, Speleman F and Van Maerken T: Inhibition of CDK4/6 as a novel therapeutic option for neuroblastoma. Cancer Cell Int 15: 76, 2015.

23. Musgrove EA, Caldon CE, Barraclough J, Stone A and Sutherland RL: Cyclin D as a therapeutic target in cancer. Nat Rev Cancer 11: 558-572, 2011.

24. Deshpande A, Pastore A, Deshpande AJ, Zimmermann Y, Hutter G, Weinkauf M, Buske C, Hiddemann W and Dreyling M: 3'UTR mediated regulation of the cyclin D1 proto-oncogene. Cell Cycle 8: 3592-3600, 2009.

25. Mitra D, Das PM, Huynh FC and Jones FE: Jumonji/ARID1 B (JARID1B) protein promotes breast tumor cell cycle progression through epigenetic repression of microRNA let-7e. J Biol Chem 286: 40531-40535, 2011.

26. Zheng L, Qi T, Yang D, Qi M, Li D, Xiang X, Huang K and Tong Q: microRNA-9 suppresses the proliferation, invasion and metastasis of gastric cancer cells through targeting cyclin D1 and Ets1. PLoS One 8: e55719, 2013.

27. Bonci D, Coppola V, Musumeci M, Addario A, Giuffrida R, Memeo L, D'Urso L, Pagliuca A, Biffoni M, Labbaye C, et al: The miR-15a-miR-16-1 cluster controls prostate cancer by targeting multiple oncogenic activities. Nat Med 14: 1271-1277, 2008.
28. Trompeter HI, Abbad H, Iwaniuk KM, Hafner M, Renwick N, Tuschl T, Schira J, Müller HW and Wernet P: MicroRNAs miR-17, miR-20a, and miR-106b act in concert to modulate E2F activity on cell cycle arrest during neuronal lineage differentiation of USSC. PLoS One 6: e16138, 2011.

29. Hermeking H: The miR-34 family in cancer and apoptosis. Cell Death Differ 17: 193-199, 2010.

30. Elliman SJ, Howley BV, Mehta DS, Fearnhead HO, Kemp DM and Barkley LR: Selective repression of the oncogene cyclin D1 by the tumor suppressor miR-206 in cancers. Oncogenesis 3: e113, 2014.

31. Buechner J, Tømte E, Haug BH, Henriksen JR, Løkke C, Flægstad T and Einvik C: Tumour-suppressor microRNAs let-7 and mir-101 target the proto-oncogene MYCN and inhibit cell proliferation in MYCN-amplified neuroblastoma. Br J Cancer 105: 296-303, 2011.

32. Roth SA, Knutsen E, Fiskaa T, Utnes P, Bhavsar S, Hald $\varnothing \mathrm{H}$, Løkke C, Mestdagh P, Johansen SD, Flægstad T and Einvik C: Next generation sequencing of microRNAs from isogenic neuroblastoma cell lines isolated before and after treatment. Cancer Lett 372: 128-136, 2016.

33. Livak KJ and Schmittgen TD: Analysis of relative gene expression data using real-time quantitative PCR and the 2(-Delta Delta C(T)) method. Methods 25: 402-408, 2001.

34. Thorsen SB, Obad S, Jensen NF, Stenvang J and Kauppinen S: The therapeutic potential of microRNAs in cancer. Cancer J 18: 275-284, 2012.

35. Witzel II, Koh LF and Perkins ND: Regulation of cyclin D1 gene expression. Biochem Soc Trans 38: 217-222, 2010.

36. Molenaar JJ, Ebus ME, Koster J, van Sluis P, van Noesel CJ, Versteeg R and Caron HN: Cyclin D1 and CDK4 activity contribute to the undifferentiated phenotype in neuroblastoma. Cancer Res 68: 2599-2609, 2008.

37. Molenaar JJ, van Sluis P, Boon K, Versteeg R and Caron HN: Rearrangements and increased expression of cyclin D1 (CCND1) in neuroblastoma. Genes Chromosomes Cancer 36: 242-249, 2003.

38. Sun F, Fu H, Liu Q, Tie Y, Zhu J, Xing R, Sun Z and Zheng X: Downregulation of CCND1 and CDK6 by miR-34a induces cell cycle arrest. FEBS Lett 582: 1564-1568, 2008. 